\title{
EEG Correlation during Social Decision-making in Institutionalized Adolescents
}

Jorge Hevia-Orozco, Araceli Sanz-Martin, Miguel Angel Guevara and Marisela Hernández-Gonzalez

Instituto de Neurociencias, Universidad de Guadalajara, Francisco de Quevedo 180, Col. Arcos Vallarta, C.P. 44130, Guadalajara, Jalisco, México

\begin{abstract}
The institutionalization is related with a deprivation of social-emotional stimulation and with alterations in the physiology of the prefrontal cortex, the electroencephalogram (EEG) and the social behavior. The aim of this study was to compare the EEG correlation during a social decision making task (Ultimatum Game) in a group of institutionalized (INST) adolescents with a never institutionalized group (NINST). The EEG correlations among prefrontal (Fp1-F3, Fp2-F4), prefronto-temporal (F3-T3, F4-T4) and prefronto-parietal (F3-P3, F4-P4) areas were recorded in 20 adolescents: 10 INST and 10 NINST. There were not differences between both groups in behavioral parameters. However, the INST group showed a higher correlation in delta and alpha-1 during the acceptance and rejection of proposals respectively, between Fp1-F3 areas. This group also presented a lower gamma correlation between F3-T3 areas during the acceptance and the rejection of proposals. Finally, INST group showed, during the acceptance of proposals, a lower gamma correlation between F3-P3 and higher F4-P4 delta correlation. These results reflect the neural characteristics of processing information from complex environments in institutionalized population and perhaps represent the bias for presentation of psychiatric conditions.
\end{abstract}

Keywords: Institutionalization; Ultimatum game; Social decisionmaking; Adolescence; EEG correlation; Early deprivation

\section{Introduction}

\section{Institutionalization}

Institutionalization is defined as any large congregate care facility in which round-the-clock professional supervision supplants the role of family-like caregivers [1]. Children are institutionalized due to different factors like abandonment, orphaning, maltreatment and also physical or mental disabilities. Many authors have related the institutionalization with a lack of stimulation in different spheres like motor, cognitive and social-affective [2-4], since factors like the absence of personalized treatment according to the ratio between infants and caregivers (15:1) [5] and the lack of quality care of caregivers [6,7] since the poor commitment for wellbeing of infants and the poor response and insensibility for the necessities of the infants [8], the round-toclock type of work [1], the constant rotation of caregiver [9] and the lack of professional training of caregivers [8] among others deficiencies. Therefore, institutionalization has been associated with consequences in brain and behavioral development.

\section{Institutionalization and brain/cognitive affectation}

Among brain areas affected by institutionalization, the institutionalized children often present lower volume of the prefrontal, temporal and parietal areas $[10,11]$ than non-institutionalized children. In addition, post institutionalized children present abnormities in some bundles that connect the different cortical areas. In this regard, several recent studies have reported a lower fractional anisotropy values in the left uncinate fasciculus and in the superior longitudinal fascicule in post institutionalized children compared to children without this personal background [12,13]. In a functional level, Chugani et al. [14] reported a reduction in glucose metabolism in the amygdala and hippocampus during rest conditions in post institutionalized children compared to never institutionalized children and neurological patients. In the EEG, it has been found a higher fronto-central and fronto-temporal coherence in institutionalized children compared to children that were previously institutionalized but were adopted before 24 months old [15]. Also, it has been found a generalized lower alpha power which is positively related to social skills according to a maturational patter found on institutionalized children placed on a foster care home before 20 months of age [16]. Finally, it has been demonstrated that the more time for children living in institutional settings, the more affectation this population suffers [17].

In relation with behavioral and cognitive consequences, diverse studies have found that the institutionalized children present impulsivity [18], social problems and delinquent behavior [19], as well as, affectation in cognitive functions like working memory, inhibitory control, memory for faces and visual attention $[2,5]$. Talking about social abilities, it has been demonstrated that children that was previously institutionalized and were randomly assigned to a foster care intervention program have better social abilities with less social communication problems compared to institutionalized children [20]. Also, it has been shown that institutionalized adolescents have less number of friends, less frequency of contacts with friends and less membership in organizations [19]. Finally, signs of alteration in the Theory of mind, a function that sustains social abilities, has been found in post institutionalized children that spent more than 6 months on institutions [3]. Therefore, perhaps in these children some executive functions, like the decision-making, express an alteration, mainly in those decisions that are presented in a highly complex context like social one.

\section{Social decision-making and brain areas}

Social decision-making is defined as those that affect oneself and

*Corresponding author: Araceli Sanz Martin, Professor-Researcher Universidad de Guadalajara Instituto de Neurociencias Francisco de Quevedo 180, Arcos Vallarta Guadalajara, Mexico, Tel: 5233 37771150; Exn: 33365; E-mail: aracelisanz@yahoo.com

Received February 14, 2017; Accepted April 20, 2017; Published April 26, 2017

Citation: Hevia-Orozco J, Sanz-Martin A, Guevara MA, Hernández-Gonzalez M (2017) EEG Correlation during Social Decision-making in Institutionalized Adolescents. Abnorm Behav Psychol 3: 131. doi: 10.4172/2472-0496.1000131

Copyright: (@ 2017 Hevia-Orozco J, et al. This is an open-access article distributed under the terms of the Creative Commons Attribution License, which permits unrestricted use, distribution, and reproduction in any medium, provided the original author and source are credited. 
others as well as immersing individual and others preferences [21]. A good option for measuring the social decision-making through the distribution of resources is the Ultimatum Game (UG) [22]. In this game one player (proposer) has the role of proposing how to split 10 dollars and the other player has the role of responding to accept or reject the proposal based on own preferences (respondent). If respondent decides to accept, the amount of money given is divided. If rejected, it is canceled and no one gets anything. For the proposer, the most rational and utilitarian propose is to provide the least amount of money for the player and for the respondent, to accept any amount of money since this is better than nothing. This game can be played in a "one shot" or in serial format [23]. In this game, the proposals can be fair or unfair; and the cognitive and neural strategies will be different in order to gain the biggest amount of money. Some studies has been focus on discover the neural basis that participate during the execution of tasks that evaluate the social decision-making.

On the other hand, the image ology techniques, has been shown that the brain areas that participate preferentially in social decision-making are the prefrontal [24] and temporal regions [25]. Although, the parietal areas have not been traditionally related with social decision-making, these can contribute to the accumulation of external information [26] and since could play an important role on this complex function [27]. Besides, these cortical areas increase their functional connectivity during a social decision-making [28]. In this regard, a technique that allows measuring the functional coupling between cortical areas is the correlation or coherence analysis of the electroencephalogram. For example, Yun [28] found a higher coherence of left prefrontal and temporal areas during the acceptance and the rejection of proposals in the UG, respectively, in healthy participants compared to schizophrenic patients.

Although is known than the institutionalized children present anatomical alterations in prefrontal and temporal cortices and in the connectivity between them, there are no studies with institutionalized adolescents. Therefore, the objective of this study was to compare the EEG correlation between prefronto-temporal areas, between prefronto-parietal areas and within the prefrontal cortex (dorsolateralfrontopolar) during the two types of responses (acceptance and rejection) of the UG between institutionalized (INST) and never institutionalized (NINST) adolescents. We hypothesize that INST will obtain less money in the UG compared to NINST. Besides, the INST group will present a lower EEG correlation among prefrontal regions, prefronto-temporal and prefronto-parietal. The study of the neural basis of the social decision-making in institutionalized adolescents in a naturalistic condition could be helpful for understanding of the long term effects of socio-emotional deprivation. Finally, we consider the importance of studying adolescents for understanding a possible cognitive and functional outcome of adverse early experiences and for considering the probable development perspective in adulthood stages. Also, this stage of life has the highest incidence of risk behaviors associated with social context, like drug consumption, sexual promiscuity and violence.

\section{Materials and Methods}

\section{Participants}

In this study participated twenty 13-16 years old male adolescents who were divided into two groups: 10 institutionalized adolescents or INST group $(n=10)$ and 10 never institutionalized adolescents or NINST group $(n=10)$ Participants of INST group had lived in the orphanage since before 4 years old, whereas, the NINST had lived with their parents. All participants were right-handed males, studied the high school, had an IQ $\geq 70$ evaluated by Wechsler Intelligent Scales $[29,30]$ and had normal scores of attention and concentration in the battery NEUROPSI [31]. They neither had current neurological and psychiatric treatment. Both groups of adolescents were matched with respect to age and IQ $(r=0.912, \mathrm{p} \leq 0.001)$.

In order to characterized the sample, the Children's PostTraumatic Stress Scale Spanish version (CPSS) [32] Spence Children's Anxiety Scale (SCAS) Spanish version [33] and Children's Depression Inventory (CDI) Spanish version [34] were applied (Table 1).

Regarding the history of INST group, access to records of each individual in the government entities responsible for the protection of minors was obtained. Records were also reviewed in the institutions where they were living. It was found that none of them had been sexually abused, and prior to entering the institution, $50 \%$ had received physical violence, $40 \%$ physical neglect and $10 \%$ psychological violence. 4 teenagers were not included in the final analysis due to they had an excessive number of EEG segments contaminated by artifacts. Institutionalized adolescents were recruited from 4 different institutions from 3 different Mexican states.

All these institutions were under the Mexican Official Norm For the Assistance Services For Children (Nom-167-SSA1-1997), confirming that the housing needs, clothing, food and health services were fully covered when the time of participation on this research project. All procedures involved in this experiment were approved by the Ethics Committee of the Institute of Neuroscience in accordance with the ethical standards laid down in the 1964 Helsinki Declaration, and all participants and their parents or tutors gave their informed consent prior to their inclusion.

\section{Ultimatum game}

For the application of the Ultimatum Game (UG), the program Multigame PC was used [35]. This game, with simultaneous EEG recording was carried out in rooms equipped to meet the basic methodological similarities (libraries, classrooms, multipurpose rooms). Each participant of INST and NINST groups always played the UG as respondent (or player 2 from here) on each session. In every single session there was another adolescent who played the role of the proposer (or player 1 from here), in the same recording room, but this participant were trained as an actor that pretended to play the Ultimatum Game, player 1 was not actually playing the game. This was done to let players 2 believe that were actually playing the game against another person. On a single session, player 1 and player 2 sat in front of each other with a respective computer and a correspondent keypad. Between computer of player 1 and computer of player 2, a USB cable connecting both computers was placed, to provoke a more realistic environment. On a single session, player 1 sat approximately 5 meters away player 2 and were then introduced at that time by the experimenter, to prevent empathic influences. At the beginning of the game, the following instructions were presented to player 2 on the

\begin{tabular}{|c|c|c|c|c|c|c|}
\hline & \multicolumn{2}{|c|}{ Institutionalized $(\mathbf{n}=\mathbf{1 0})$} & \multicolumn{2}{|c|}{ Never institutionalized $(\mathbf{n = 1 0})$} & \multicolumn{2}{c|}{ Comparisons } \\
\hline & $\mathrm{M}$ & $\mathrm{SE}$ & $\mathrm{M}$ & $\mathrm{SE}$ & $\mathrm{t}$ & $\mathrm{p}$ \\
\hline Age & 14.8 & 1.033 & 14.1 & 0.738 & 1.74 & 0.098 \\
\hline $\mathrm{IQ}$ & 88.9 & 14.07 & 85.0 & 8.62 & 0.75 & 0.463 \\
\hline $\mathrm{CDI}$ & 48.5 & 2.34 & 42.11 & 2.24 & 1.826 & 0.085 \\
\hline CPSS & 18.3 & 5.24 & 5 & 1.8 & 2.402 & $\mathbf{0 . 0 3 5}$ \\
\hline SCAS & 59.2 & 2.021 & 51.2 & 4.09 & 1.754 & 0.097 \\
\hline
\end{tabular}

Table 1: Demographic characteristics and psychopathological symptoms of the participants of both groups. 
screen: 1) you are playing the Multigame PC with the other adolescents has just met, 2) the other adolescent is going to make a proposal of how to split $\$ 10,3)$ you can accept or reject the proposal, 4) if you accept the proposal, the money will be split between you and the other participant, but if you reject it, neither you nor the other will receive the money, 5) you will received the proposals immediately from the other computer (from player 1) through the USB cable 6) at the end of the research, each one will receive half the accumulated money. Since player 1 was not actually playing the game, proposals were pre design before starting the research project and were divided in 3 trials with 20 proposals each in every session. The rate of fair and unfair proposals on each trial was $75 \%$ of unfair proposals and $25 \%$ of fair proposals. Firstly, the participant played 1 training trial with 5 proposals to become familiar with the game. At the end of this trial, the understanding of the rules (displayed below) and dynamics of UG, were confirmed. Only adolescents from INST receive the money accumulated at the end of the research. The total amount of money accumulated that was gain through the acceptance and the rejection of proposals were measured.

\section{EEG recording}

EEG recordings were taken at six derivations of the International 10/20 System. Electrodes were placed in prefrontal areas like frontopolar (Fp1, Fp2) and dorsolateral (F3, F4) areas and in temporal (T3, T4) and parietal (P3, P4) areas. All derivations were referred to linked ears with the ground electrode placed on the forehead. Electroculogram were recorded to detect eye-movement artifacts using a monopolar montage with electrodes placed at the outer canthi of both eyes. The EEG signals were digitally amplified with a Neuroscan-NuAmps digital amplifier, with EEG filters set at 1 and $50 \mathrm{~Hz}$. Impedance for the EEG electrodes was kept below $10 \mathrm{kV}$ using Neuroscan silver chloride electrodes. EEG signals were simultaneously recorded in the computer through the program Scan 4.3 Software. For the analysis of EEG segments were processed epochs link to the acceptance or rejection of proposals $( \pm$ $500 \mathrm{~ms}$ ). The EEG epochs that were visually identified as contaminated by noise were removed manually using a computer program named CHECASEN [36] and contaminated segments were eliminated. Later, EEGs were analyzed by the EEGBands computer program [37], which initially calculated the Fast Fourier Transform (FFT) to seven frequency bands: delta $(1.5-3.5 \mathrm{~Hz})$, theta $(3.5-7.5 \mathrm{~Hz})$, alpha-1 (7.5$10.5 \mathrm{~Hz})$, alpha-2 (10.5-13.5 Hz), beta-1 (13.5-19.5 Hz), beta-2 (19.5$30 \mathrm{~Hz})$ and gamma $(31-50 \mathrm{~Hz})$. The correlation spectrum $(r)$ was then calculated from the auto spectra and the cross-spectrum of the signals' proportioning values between -1 and +1 . Correlation spectra at 0 delay for each subject and condition were obtained for each frequency band using amplitude values by means of Pearson product-moment coefficients to obtain intrahemispheric correlations (INTRAr) between derivations in the right (Fp2-F4, F4-T4, F4-P4) and left (Fp1-F3, F3T3, F3-P3) hemispheres. Correlation values were transformed to Fisher's z-scores to approximate them to a normal distribution before conducting the statistical procedure. Z-score calculations were based on individual scores.

\section{Procedure}

The two groups were evaluated in the following manner: first, contact was made with the orphan institutions to get the permission to invite adolescents who met the inclusion criteria. In the case of control group the recruitment took place in a junior high school. After permission to participate by parents or caregivers was obtained, was settled the appointment for psychometric tests. The study was conducted in two sessions: in the first meeting attention, concentration, IQ, Depression, Anxiety and Posttraumatic Stress Disorder test were applied. In a later session the EEG during the Ultimatum Game was recorded.

\section{Statistical Analysis}

For the demographic characteristics and behavioral parameter total amount of money accumulated, were performed a t-test between institutionalized and never institutionalized adolescents. In the EEG analyses, we used two-factor ANOVAs (2 groups $\mathrm{x} 2$ type of responses [accepted and rejected]) for each pair of the intrahemispheric derivations (Fp1-F3, Fp2-F4, F3-T3, F4-T4, F3-P3, and F4-P4) in each frequency band. A Tukey test was performed afterwards at a significance level of 0.05 .

\section{Results}

\section{UG performance}

The t-test for behavioral parameter total amount of money accumulated did not reflect differences between groups (INST, $M=113$, $\mathrm{E} . \mathrm{S}=8.260$, NINST, $\mathrm{M}=119.9, \mathrm{E} . \mathrm{S}=4.552, \mathrm{p} \leq 0.495$ ), so that both groups had the same amount of money accumulated at the end of the game.

\section{EEG correlations}

In the right dorsolateral-front polar correlation (Fp2-F4), there was no significant differences between-groups neither in the acceptance nor the rejection of the proposals. However, between pairs of electrodes Fp1-F3, it was found a higher correlation in the INST group compared to NINST group in delta band during the acceptance of the proposals $\left(\mathrm{F}_{1.27}\right.$ 15.48, $\left.\mathrm{p} \leq 0.015\right)$ (Figure 1, left) as well as a higher correlation in the INST group compared to NINST group in the alpha- 1 band during
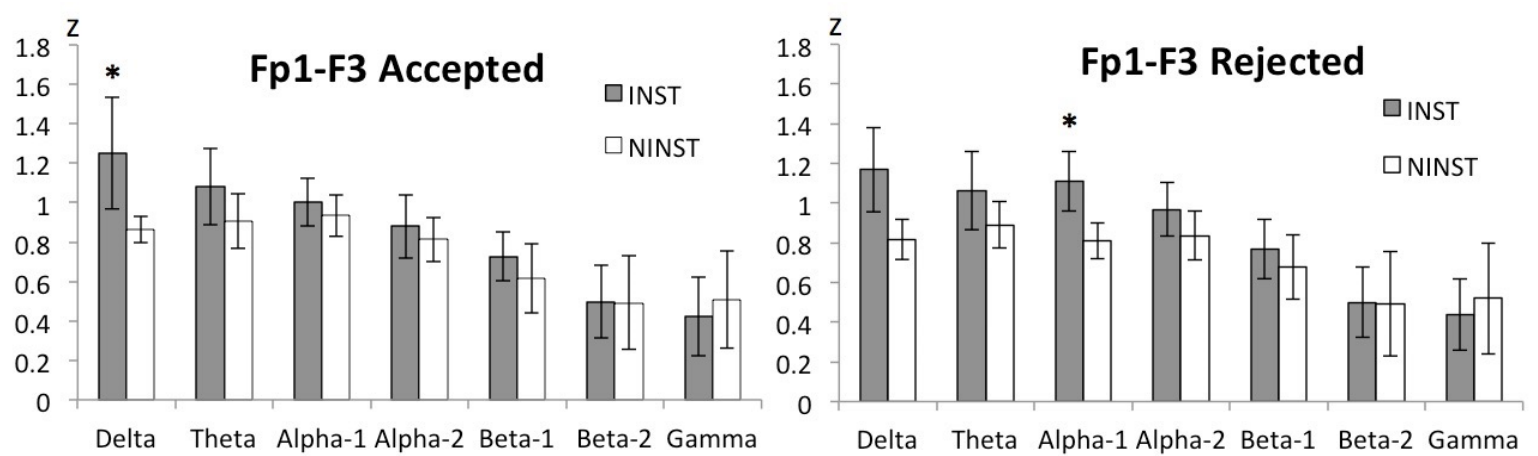

Figure 1: Represents the higher presence of slow bands (delta and alpha-1) in the EEG correlation between Fp1-F3 during the acceptance (left) and during the rejection (right) of proposals in the INST group (mean \pm 2 S.E). 


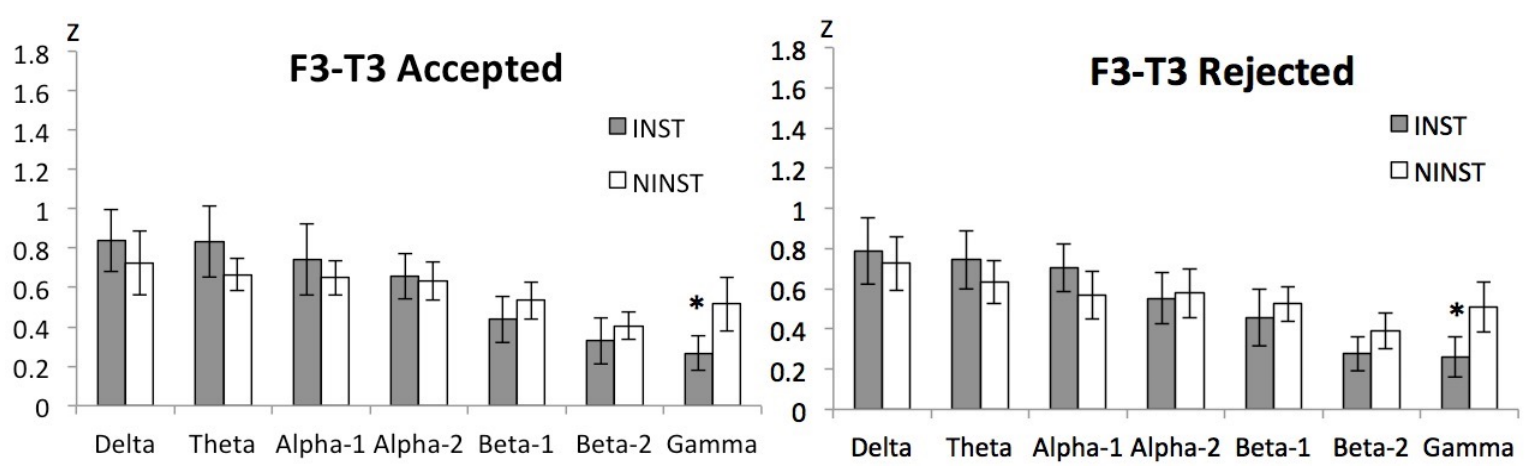

Figure 2: Represents the lower presence of fast band (gamma) in the EEG correlation between F3-T3during the acceptance (left) and during the rejection (right) of proposals in the INST group (mean \pm 2 S.E).

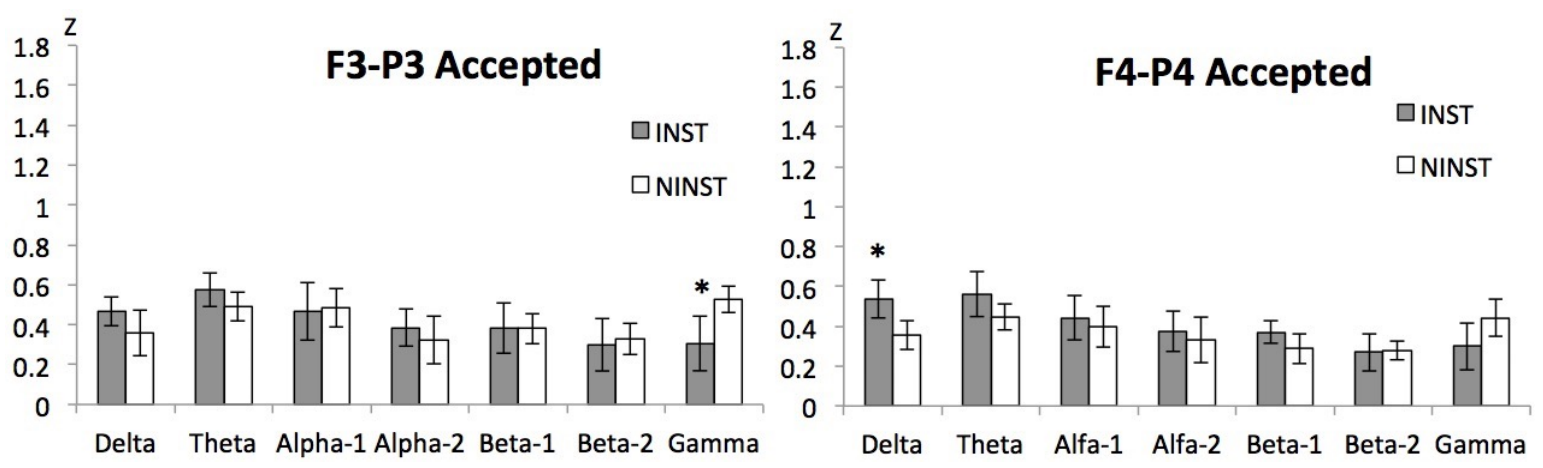

Figure 3: Represents the lower presence of fast band (gamma) and higher presence of slow band (delta) in the EEG correlation between F3-P3 and F4-P4, respectively during acceptance of proposals in the INST group (mean \pm 2 S.E).

the rejection of the proposals $\left(\mathrm{F}_{1.27} 9.39, \mathrm{p} \leq 0.003\right)$.

Between right dorsolateral and temporal areas (F4-T4) there were no differences between groups. Between pairs of electrodes F3-T3, it was found a lower correlation in the INST group compared to NINST group during acceptance $\left(\mathrm{F}_{1,27}=4.30, \mathrm{p} \leq 0.006\right)$ (Figure 2, left) and during the rejection of proposals $\left(\mathrm{F}_{1,27=} 4.30, \mathrm{p} \leq 0.007\right)$ (Figure 3 , right) in gamma band.

In the correlation between left dorsolateral and parietal areas (F3P3) it was found a lower correlation in the INST group compared to NINST group $r$ in the gamma band during acceptance of proposals $\left(\mathrm{F}_{1,27}=14.88, \mathrm{p} \leq 0.009\right)$ (Figure 3 , left) as well as a higher correlation in the INST group compared to NINST group in delta band in the right hemisphere ( $\mathrm{F} 4-\mathrm{P} 4)\left(\mathrm{F}_{1,27}=6.63, \mathrm{p} \leq 0.006\right)$ (Figure 3, right). There were not interactions between groups.

\section{Discussion}

In this study we compared the functional prefronto-temporal, prefronto-parietal and within prefrontal coupling through EEG correlation between the INST group and the NINST group during the execution of a computerized version of the Ultimatum Game. We found a lower EEG correlation between prefrontal and temporal areas in the gamma band in the institutionalized group during both the rejection and acceptance of proposals. Also we found a lower and higher EEG correlation between right and left prefrontal and parietal areas only during the acceptance of proposals, respectively, in the INST group compared to NINST group. In addition, we found a left higher EEG correlation between prefrontal and frontopolar areas during the acceptance of proposals and a higher EEG correlation between same areas but during rejection of proposals, both in INST compared to NINST.

\section{Ultimatum game performance}

According to the pattern of impulsivity described on this group in previous works [18], we expected a lower amount of money accumulated in the institutionalized group as a result of a series of emotional reactions related with unfair proposals $(75 \%$ of the total trials). INST adolescents would be less able to sacrifice some financial gain in order to get some money perhaps according to a higher socioemotional reactivity. However, there were no differences between groups, so both groups got a mean of $\$ 120$ pesos. If both groups would have accepted every proposal, they had gotten $\$ 185$. It is necessary to consider that both groups comes from a low income socioeconomic status where the accessibility to money is not as easier as would be on higher socioeconomic status, therefore it could be that both groups were not able to sacrifice certain amount of money. However, more studies are needed to confirm the incentive value of money in lowincome population.

\section{EEG correlation}

Regarding our finding of the left higher correlation in the delta band between Fp1-F3 during the acceptance of unfair proposals in INST adolescents regarding NINST, other studies have found similar results in delta band during the execution of Wisconsin Card Sorting Test in sexual abused adolescents [38]. Also, higher delta band coherence was found on learning-disabled children, compared to a control group, between left prefrontal electrodes [39] and in children that come from low-income families [40]. Besides, delta band has been associated with immaturity [41].

It necessary to mentioned that in the baseline of both groups (EEG 
in rest), we obtained significant differences between groups in delta band correlation (in preparation), so the higher correlation in this band in INST adolescences could be related to structural immaturity in the left prefrontal cortex instead of processes related with cognitive abilities needed for playing the Ultimatum Game. This pattern of immaturity could be perhaps related with the lack of functional connectivity between VMPFC, DLPFC, VlPFC, insula thalamus, hippocampus, amygdala and cerebellum [42], associated with the lack of cognitive and affective stimulation that is derived by institutional rearing mentioned before. This finding also remark the sensibility of delta band to environmental factors and cognitive stimulation since previous reports have shown a gradual decrease of the slow bands such as delta, during the execution of the Continuous Performance Task in a group of children assigned to an enrichment of the environment in a nursery [43].

On the other hand, we found in INST participants a left higher correlation in the alpha-1 band between Fp1-F3 during the rejection of proposals. We consider that this reaction could be reflected a decrease in approach motivation in the face to the injustice [44]. Previous studies have found an increase of the activity of left prefrontal activation in approach motivation whereas the activation of the right prefrontal region has been associated with withdrawal motivation [45]. In addition, alpha band is inversely related with the activity of the cerebral cortex [46], so that, the presence of a greater correlation between anterior and dorsolateral prefrontal regions in alpha- 1 band could be reflecting a decrease in approach motivation on a social decision-making in INST participants. Consequently, INST adolescents could have had a deficit in the motivation to try to change the unfair proposals. This idea could be related to "learned helplessness" in which the subject learns that cannot escape to an adverse and stressful event since a lack of control over it and hence has a lack of runaway motivation [47]. In this model, as the institutionalized population, the results are not under control of the individual. Again, these ideas are not far from the daily reality of the institutionalized population where they do not have control over important situations like being adopted or spend time with their relatives.

INST adolescents presented lower gamma correlation between left prefrontal and temporal regions during the acceptance and the rejection of the proposals. We consider that this result could indicate difficulties in the social-emotional processing due to alterations in the functional connectivity between prefrontal and temporal regions. In this instance, it is known that temporal areas have been linked to social information processing [48] and with the Theory of Mind [49], whereas, dorsolateral prefrontal cortex, has been associated with the manipulation of the information for the decision-making [50] independently of the semantic meaning, in this case the socioemotional [51]. Therefore, the functional coupling between prefrontal and temporal areas could participate in the manipulation of socialemotional information and this coupling is in part performed by uncinate fasciculus which provides strong connections between those regions [52]. This bundle, in the left hemisphere, shows a lower density in the institutionalized population $[12,13]$. Related with the communication between areas, gamma band has been related with this function on other works [53]. Consequently, the lower correlation between frontal and temporal regions in gamma bands could be a result of the alteration of uncinate fasciculus. It is remarkable to mention that similar EEG characteristics have been found in schizophrenic patients during both types of responses during the Ultimatum Game [28]. Thus, the lower fronto-temporal correlation in gamma band in institutionalized adolescents could be indicating a predisposition to develop psychiatric illnesses. Similarly, INST group showed a lower left prefronto-parietal correlation in gamma band during the acceptance of proposals which could be related to a disturbance in left anatomical connectivity between prefrontal and parietal areas and thereby problems in the understanding of others-perspective involved in the social decision. The frontal and parietal cortices are connected directly through superior longitudinal fasciculi [54] and this tract shows a lower density in institutionalized population [13]. Besides, left parietal cortex has been related with others-perspective decision-making and right parietal cortex with own-perspective decision-making $[27,55,56]$. Regarding this interpretation, it has been found that lower prefrontoparietal coherence in gamma band is related with low trait emphatic concern (and higher scores of psychopathy) in normal adults [57].

On the other hand we found a higher delta correlation in right prefronto-parietal regions also during the acceptance responses in the INST group. It has been mentioned above that right parietal lobule was related before with the own-perspective decision-making. It is interesting to consider that delta band coherence between prefrontal and parietal areas was found as modulated by the decision-making related with the attention processes needed for the decision [58]. Therefore, it could be plausible to consider that INST adolescents are more prone to considering their own-perspective contribution to the decision.

An important finding of this research was the predominance of lower EEG correlation in left hemisphere since previous works have described also EEG differences in left hemisphere in adolescents with severe physical or sexual abuse background [38,59], violent subjects [60] or serial killer [61]. This EEG characteristic could be understood under the light of the "Bi hemispheric Autonomic Model" [62] which supposes that the normal reaction during anxiogenic situations (as a child being neglected) is mediated by right hemisphere, through the sympathetic system, with the activation and release of different systems and neurotransmitters like epinephrine and norepinephrine. However, in order to reduce the stress related activation, the left hemisphere increases its activation through the parasympathetic system, which supplies a management of the autonomic system. Along the normal brain development, perhaps, a depletion of this system could provoke an alteration in input signals from subcortical structures to medial prefrontal cortex [63]. This could lead to a strong bias in behavior in a non-functional manner becoming the normal leftward hemispheric reaction from physiological to pathological condition. Behaviors like freeze, shutdown or retreat are examples of these processes and if persisting it will prevent healthful engagement with life by most any reasonable measure. This would explain behavioral characteristic in institutionalized adolescents like social withdrawn, internalizing problems and thought problems [19] and our EEG results and other research left-lateralized findings. It is remarkably to consider that, our participants do not have motor nor alimentary deprivation, so that the lack of emotional or psychological availability could be the main factor related with left-lateralized EEG findings. However more studies are needed to deep about this explanation with the presence of slow bands and the lack of functional connectivity between prefrontal and other structures.

Some authors have identified that institutionalized population has some quasi-autistic cognitive characteristics [64,65] since both institutionalized children and autistic patients have impaired social performance although the institutionalized group presents greater flexibility, greater social approach and an increased incidence of indiscriminate friendly compared to children diagnosed with autism 
[66]. It is noteworthy that both institutionalized children and autistic patients have characteristics of abnormal connectivity between prefrontal and parietal regions [13,67] and between prefrontal and temporal regions $[12,68]$, that perhaps are related with cognitive and behavioral similarities at school age (4-6 years). However, these similarities become less clear in the adolescence and hence only a small group of institutionalized adolescents have a permanent quasi-autistic pattern upon turning 11 years [65]. Also, the same EEG characteristics between prefrontal and temporal cortices have been found in schizophrenic patients during accepted and rejected proposals in execution of the Ultimatum Game [28]. Of great interest would deepen on the mechanism that derives on these electrophysiological differences between groups to determine the probability for presentation of psychiatric disorders in the future in institutionalized adolescents or other type of maltreatment population. These EEG characteristics could suggest that INST group has a predisposition to develop some psychopathologies with social abilities affected like in schizophrenia but this possibility should be explored in future studies.

Finally, it is important to mention some limitations of the present work. The first of them has to do with the smallness of the sample despite the fact that the INST participants were recruited from foster homes of three different Mexican states. Many institutionalized adolescents were not included since artifact problems in the EEG, low IQ, current psychopharmacological treatment or very low scholarship. Another limitation was that many of the children in Mexico are admitted to the foster homes after the school age so they could not be part of our sample. We look for teenagers who had been institutionalized before 4 years of age. Therefore, the scarce numbers of participants were related with the lack of participants available for this project.

The second limitation was the difficulty to include participants without any kind of abuse and psychopathology. In Latin America the main reasons why children are institutionalized are by some type of violence and other stressing situations as poverty, partial or total orphans, street situations, irregular migrants, natural disasters, drug abuse, psychiatric illness or illness that makes them unable or because their parents are deprived of their liberty. So, the results in the present study may be a product of the coexistence of the socio-emotional deprivation proper to the institutionalization and the early stress that the participants suffered before entering to this alternative care system. We consider that it is necessary more investigation with this kind of population in order to differentiate the effects of child abuse and the institutionalization. It is important to mention that although the INST and NINST groups come from very different contexts, the participants of both groups were matched according to their age, schooling, IQ and socioeconomic level. For this reason, we consider that the NINST group was an adequate control. Another limitation of this study was the lack of more detailed behavioral parameters due to technical problems during the collecting of data.

\section{Conclusion}

Although there were not significant behavioral differences between groups, EEG differences were clear. Perhaps the differences in functional coupling within prefrontal cortex and between prefrontal and temporal and parietal cortices are revealing some deficiencies in social abilities. These EEG findings could represent a predisposition for psychopathological conditions for the future.

\section{Acknowledgements}

We thank to CONAYCT with the grant 290840 and CB/2012/180981 and
Carlos Del Castillo Award for supporting this project. We also thank to different institutions that kindly contributed with this research project: Procuraduria de la Defensa del Menory la Familia (PRODEMEFA) of the Sistema Integral de la Familia (DIF) of the state of Yucatán, México and to orphan institutions: Comunidad de Restauración Integral de Adolescentes (CRIAI.A.P.), Centro de Atención Integral al Menor en Desamparo (CAIMEDE) in Mérida, Yucatán, Hogar Cabañas in Guadalajara, Jalisco and Cancún Pro Kids in Cancún Quintana Roo, for their support. Finally, to different collaborators that technically contributed to this project.

\section{References}

1. Berens A, Nelson CA (2015) The science of early adversity: Is there a role for large institutions in the care of vulnerable children? The Lancet 386: 388-398.

2. Bos K, Fox N, Zeanah CH, Nelson III CA (2009) Effects of early psychosocial deprivation on the development of memory and executive function. Front Behav Neurosci 3: 1-7

3. Colvert E, Rutter M, Kreppner J, Beckett C, Castle J, et al. (2008) Do Theory of Mind and Executive Function Deficits Underlie the Adverse Outcomes Associated with Profound Early Deprivation? Findings from the English and Romanian Adoptees Study. J Abnor Child Psychol 36: 1057-1068.

4. Levin AR, Zeanah CH, Fox NA, Nelson CA (2014) Motor outcomes in children exposed to early psychosocial deprivation. J Pediatr164: 123-129.

5. Pollak SD, Nelson CA, Schlaak MF, Roeber BJ, Wewerka SS (2011) Neurodevelopmental Effects of Early Deprivation in Post- Institutionalized Children. Child Dev 81: 224-236.

6. Bakersman-Kranenburg $\mathrm{M}$, Steele $\mathrm{H}$, Zeanah $\mathrm{CH}$, Muhamedrahimov R, Vorria $\mathrm{P}$, et al. (2011) Attachment and emotional development in Institutional Care: Characteristics and Catch Up Monogr Soc Res Child Devel 76: 62-91.

7. The St.Petersburg-USA Orphanage Research Team (2010) The Effects of Early Social-Emotional And Relationship Experience on the development of young orphanage children. Monogr Soc Res Child Devel 73: 1-276.

8. Nelson CA (2007) A neurobiological perspective on early human deprivation Child Dev Perspect1: 13-18.

9. Bick J (2012) The Science of Neglect-The Persistent Absence of Responsive Care Disrupts the Developing Brain. Center on the Developing Child.

10. Hodel AS, Hunt RH, Cowell RA, Van Den Heuvel SE, Gunnar MR (2015) Duration of early adversity and structural brain development in postinstitutionalized adolescents. Neuroimage105: 112-119.

11. McLaughlin KA, Sheridan MA, Winter W, Fox NA, Zeanah CH (2014) Widespread reductions in cortical thickness following severe early-life deprivation: A neurodevelopmental pathway to attention-deficit/hyperactivity disorder. Biol Psychiatry76: 629-638.

12. Eluvathingal TJ (2006) Abnormal Brain Connectivity in Children After Early Severe Socioemotional Deprivation: A Diffusion Tensor Imaging Study. Pediatrics117: 2093-2100.

13. Govindan RM, Behen ME, Helder E, Makki MI, Chugani HT (2010) Altered water diffusivity in cortical association tracts in children with early deprivation identified with tract-based spatial statistics (TBSS). Cereb Cortex 20: 561-569.

14. Chugani H, Behen M, Muzik O, Juhász C, Nagy F, et al. (2001) Local Brain Functional Activity Following Early Deprivation: A Study of Post institutionalized Romanian Orphans. Neuroimage 14: 1290-1301.

15. Marshall P, Reeb B, Fox N, Nelson III CA, Zeanah CH (2008) Effects of Early Intervention on EEG Power and Coherence in Previously Institutionalized Children in Romania. Dev Psychopathol 20: 861-880.

16. Almas A, Degnan K, Radulescu A, Nelson III CA, Zeanah CH (2012) Effects of early intervention and the moderating effects of brain activity on institutionalized children's social skills at age 8. Proc Natl Acad Sci 109: 1728-1231.

17. McLaughlin KA, Sheridan MA, Tibu F, Fox NA, Zeanah CH (2015) Causal effects of the early caregiving environment on development of stress response systems in children. Proc Natl Acad Sci112: 5637-5642.

18. McDermott J, Westerlund A, Zeanah CH, Nelson CA, Fox N (2012) Early adversity and neural correlates of executive function: Implications for academic adjustment. Dev Cogn Neurosci 15: 59-66.

19. Erol N, Simsek Z, Münir K (2010) Mental health of adolescents reared in institutional care in Turkey: challenges and hope in the twenty-first centur. Eur Child Adolesc Psychiatry 19: 113-124. 
Citation: Hevia-Orozco J, Sanz-Martin A, Guevara MA, Hernández-Gonzalez M (2017) EEG Correlation during Social Decision-making in Institutionalized Adolescents. Abnorm Behav Psychol 3: 131. doi: 10.4172/2472-0496.1000131

20. Levin A, Fox N, Zeanah Ch, Nelson CA (2015) Social Communication Difficulties and Autism in Previously Institutionalized Children. J Am Acad Child Adolesc Psychiatry 54

21. Rilling JK, Sanfey AG (2011) The Neuroscience of Social Decision Making. Annu Rev Psychol 62: 23-48.

22. Güth W, Schmittberger R, Schwarze B (1982) An experimental analysis of ultimatum bargaining. J Econ Behav Organ 3: 367-388.

23. Yun K, Chung D, Jeong J (2008) Emotional Interaction in Human Decision Making using EEG Hyperscanning. Proceedings of the 6th International Conference on Cognitive Science.

24. Knoch D, Pascual-Leone A, Meyer K, Treyer V, Fehr E (2006) Diminishing reciprocal fairness by disrupting the right prefrontal cortex. Science 314: 829-832.

25. Rilling JK, Sanfey AG, Aronson JA, Nystrom LE, Cohen JD (2004) The neura correlates of theory of mind within interpersonal interactions. Neuroimage 22 1694-1703.

26. Hanks TD, Kopec CD, Brunton BW, Duan CA, Erlich, JC (2015) Distinct relationships of parietal and prefrontal cortices to evidence accumulation. Nature 520: 220-223.

27. Lamm C, Batson CD, Decety J (2007) The neural substrate of human empathy: effects of perspective-taking and cognitive appraisal. J Cognitive Neurosci 19 : $42-58$

28. Yun K (2010) Neural mechanisms of decision making in the Ultimatum Game in the context of interactions between emotion and reason. Doctoral Dissertation, Department of Bio and Brain Engineering KAIST.

29. Wechsler D (1997) Escala de Inteligencia para Adultos, WAIS-Español. México DF, México: El Manual Moderno.

30. Wechsler D (2003) Wechsler Intelligence Scale for Children (WISC-IV). San Antonio, Texas, E.E.U.U: Psychological Corporation.

31. Ostrosky-Solis F, Gómez M, Matute E, Roselli M, Ardila A (1997) Neuropsi Atención y Memoria. Manual Moderno, México, D.F.

32. Bustos $P$, Rincón P, Aedo J (2009) ValidaciónPreliminar de la Escalalnfantil de Síntomas del Trastorno de EstrésPostraumático (Child PTSD Symptom Scale, CPSS) en Niños/as y Adolescentes Víctimas de Violencia Sexual. Psykhe 18: 113-126.

33. Spence S, Barrett P, Turner C (2003) Psychometric properties of the Spence Children's Anxiety Scale with young adolescents. Anxiety Disorders 17: 605-625.

34. Kovacs M (2004) Inventario de DepresiónInfantil (CDI). TEA Ediciones, España.

35. Hevia-Orozco J, Sanz-Martín A, Hidalgo-Aguirre RM, Hernández-González M, Guevara MA (2014) Evaluación de la toma de decisiones sociales a través de Ultimatum Game versión computarizada. eNeurobiología 5: 1-11.

36. Guevara M, Sanz-Martin A, Corsi-Cabrera M, Amezcua-Gutierrez C Hernández-González M (2010) Checasen: un programa para revisar señales EEG fuera de línea. Revista Mexicana de ingenieríabiomedica 31: 135-141.

37. Guevara MA, Sanz-Martin A, Hernández-González M (2014) EEGbands: A Computer Program to Statistically Analyze Parameters of Electroencephalographic Signals 4: 308-324

38. Rizo-Martínez L, Sanz-Martin A, Guevara MA, Hernández-González A Inozemtseva O, et al. (2015) EEG Correlations during WCST Performance in Female Adolescents with Sexual Abuse-Related Post-Traumatic.

39. Marosi E, Harmony T, Sánchez L, Becker J, Bernal J, et al. (1992) Maturation of the coherence of EEG activity in normal and learning-disabled children. Electroencephalogr Clin Neurophysiol 83: 350-357.

40. Harmony T, Marosi E, Díaz de León AE, Becker J, Fernández T (1990) Effect of sex, psychosocial disadvantages and biological risk factors on EEG maturation. Electroencephalogr Clin Neurophysiol 75: 482-491.

41. Gasser T, Rousson V, Schreiter Gasser U (2003) EEG power and coherence in children with educational problems. J Clin Neurophysiol 20: 273-282.

42. Wang L, Dai Z, Peng H, Tan L, Ding Y, et al. (2014) Overlapping and segregated resting-state functional connectivity in patients with major depressive disorder with and without childhood neglect. Hum Brain Mapp 35: 1154-1166.

43. Raine A, Venables PH, Dalais C, Mellingen K, Reynolds C (2001) Early educational and health enrichment at age 3-5 years is associated with increased autonomic and central nervous system arousal and orienting at age 11 years: evidence from the Mauritius Child Health Project. Psychophysiology 38: $254-266$.

44. Sanfey A, Rilling J, Aronson A, Nystrom L, Cohen J (2003) The Neural Basis of Economic Decision-Making in the Ultimatum Game. Science 300: 1755-1758.

45. Harmond-Jones E, Sigelman J (2001) State Anger and Prefrontal Brain Activity Evidence That Insult-Related Relative Left-Prefrontal Activation is Associated with Experienced and Anger. J Pers Soc Psychol 80: 797-803.

46. Davidson RJ, Ekman P, Saron CD, Senulis JA, Friesen WV (1990) Approachwithdrawal and cerebral asymmetry: emotional expression and brain physiology: I. J Pers Soc Psychol 58: 330-341.

47. Mikulnicer M, Nizan B (1988) Causal Attribution, Cognitive Interference, and the Generalization ofLearned Helplessness. Journal of Personality and Social Psychology 55: 470-478.

48. Simmons WK, Reddish M, Bellgowan PSF, Martin A (2010) The selectivity and functional connectivity of the anterior temporal lobes. Cereb Cortex 20: 813-825.

49. Lewis PA, Rezaie R, Brown R, Roberts N, Dunbar RIM (2011) Ventromedia prefrontal volume predicts understanding of others and social network size. Neuroimage 57: 1624-1629.

50. Krawzyk D (2002) Contributions of the prefrontal cortex to the neural basis of human decision-making. Neurosci Biobehav Rev 26: 631-664.

51. Nystrom LE, Braver TS, Sabb FW, Delgado MR, Noll DC, (2000) Working memory for letters, shapes, and locations: fMRI evidence against stimulusbased regional organization in human prefrontal cortex. Neuroimage11: 424-46.

52. Thiebaut de Schotten M, Dell'Acqua F, Valabregue R, Catani M (2012) Monkey to human comparative anatomy of the frontal lobe association tracts. Cortex48: 82-96.

53. Varela F, Lachaux J, Rodríguez E, Martinerie J (2001) The Brainweb: Phase Synchronization And Large-Scale Integration. Nat Rev Neurosci 2: 229-239.

54. Fuster JM (2008) The Prefrontal Cortex: Anatomy of the prefrontal cortex. Academic Press, Oxford, UK

55. Van den Bos W, van Dijk E, Westenberg M, Rombouts S, Crone E (2011) Changing Brains, Changing Perspectives: The Neurocognitive Development of Reciprocity. Psychol Sci 22: 60-70.

56. Vogeley K, Bussfeld P, Newen A, Herrmann S, Happé F, et al. (2001) Mind Reading: Neural Mechanisms of Theory of Mind and Self-Perspective. Neuroimage 14: $170-181$.

57. Decety J, Lewis KL, Cowell JM (2015) Specific electrophysiological components disentangle affective sharing and empathic concern in psychopathy. J Neurophysiol114: 493-504

58. Nácher V, Ledberg A, Deco G, Romo R (2013) Coherent delta-band oscillations between cortical areas correlate with decision making. Proc Natl Acad Sci110: 15085-15090.

59. Miskovic V, Schmidt L, Georgiades K, Boyle M, Macmillan HL (2010) Adolescent females exposed to child maltreatment exhibit atypical EEG coherence and psychiatric impairment: linking early adversity, the brain, and psychopathology. Dev Psychopathol 22: 419-432.

60. Convit A, Czobor P, Volavka J (1991) Lateralized abnormality in the EEG of persistently violent psychiatric inpatients. Biol Psychiatry30: 363-370.

61. Ostrosky-Solís F, Vález-García A, Santana-Vargas D, Pérez M, Ardila, A (2008) A middle-aged female serial killer. J Forensic Sci 53: 1223-1230.

62. Lee SW, Gerdes L, Tegeler CL, Shaltout HA, Tegeler CH (2014) A bihemispheric autonomic model for traumatic stress effects on health and behavior. Front Psychol 5: 1-14

63. Brozoski TJ, Brown RM, Rosvold HE, Goldman PS (1979) Cognitive Deficit Caused by Regional Depletion of Dopamine in Prefrontal Cortex of Rhesus Monkey. Science205: 929-932.

64. Nelson III CA, Bos K, Gunnar M, Sonuga-Barke E (2011) The Neurobiologica Toll of Early Human Deprivation. Monogr Soc Res Child Dev 76: 127-146.

65. Rutter M, Kreppner J, Croft C, Murin M, Colvert E, et al. (2007) Early adolescent outcomes of institutionally deprived and non-deprived adoptees. III. Quasiautism. J Child Psychol Psychiatry 28: 1200-1207. 
Citation: Hevia-Orozco J, Sanz-Martin A, Guevara MA, Hernández-Gonzalez M (2017) EEG Correlation during Social Decision-making in Institutionalized Adolescents. Abnorm Behav Psychol 3: 131. doi: 10.4172/2472-0496.1000131

Page 8 of 8

66. Bos K, Zeanah CH, Fox N, Drury S, McLaughlin K, et al. (2011) Psychiatric Outcomes in Young Children with a History of Institutionalization. Harv Rev Psychiatry 19: 15-24.

67. Just M, Cherkassky V, Keller T, Kana R, Minshew N (2007) Functional and anatomical cortical underconnectivity in autism: Evidence from an fMRI study of an executive function task and corpus callosum morphometry. Cereb cortex 17: $951-961$

68. Shukla DK, Keehn B, Müller RA (2011) Tract-specific analyses of diffusion tensor imaging show widespread white matter compromise in autism spectrum disorder. J Child Psychol Psychiaty52: 286-295. 